\title{
A Year of Change and Further Changes Ahead
}

The Canadian Journal of Neurological Sciences (CJNS) has undergone major changes in the past year. The Canadian Neurological Sciences Federation (CNSF) board and CJNS Editorial Board studied different publication options for the journal and examined proposals from several publishers. We are delighted to have Cambridge University Press as our publisher. This worldclass organization, with their mission of disseminating knowledge and scholarly work, fits well with the goals of our journal. We are impressed by the professionalism, expertise, and dedication of the staff at Cambridge University Press. In addition, I would like to thank Cindy Leschyshyn and Maggie McCallion, who left the $C N S F$ office in May 2014, for their many years of dedicated work for the journal.

In April 2014, our manuscript submission and processing website was changed to a site hosted by Scholar One (https://mc. manuscriptcentral.com/cjn). We thank our many authors for their patience during this transition process. Our new journal website (http://journals.cambridge.org/cjn) became operational in September 2014. The transition led to a delay in posting the September CJNS issue, and we thank CNSF members for their patience. The website now functions very well and contains volumes of the journal from 1999 to the present. All journal articles published more than one year ago (up to 2013 at the time of this writing) are freely available.

We also have implemented several changes to CJNS. We introduced "FirstView," with publication of manuscripts within a few weeks of acceptance. This significantly shortens the time from acceptance to publication and is a benefit to our authors and readers. We added key words for new articles to increase the visibility of our articles from literature searches.

Our readers will see further changes to the journal in the new year. There is currently no electronic access to the legacy issues of CJNS before 1999, but CNSF members will soon have electronic access to all journal articles since its inception in 1974. Although CJNS is currently online only, CNSF members will have the option of receiving the print journal with a "print on demand" feature offered by Cambridge University Press. We expect an increase in the number of review articles in the coming year.
One of our goals is to improve the basic science contents of the journal. Several speakers at the 2014 Canadian Association of Neuroscience and CNSF annual meetings have agreed to contribute review articles; I believe our readers will find these articles useful and informative.

In the past year, we also had changes in the Associate Editors for the journal. Mike Poulter, our basic science Associate Editor; Mark Sadler and Serge Gauthier, Associate Editors for neurology; and Max Findlay, Associate Editor for neurosurgery; have stepped down. We are very grateful for their many years of outstanding service to the journal. We welcome our new Associate Editors: Edward (Ted) Fon from McGill University for basic science, Tejas Sankar from the University of Alberta for neurosurgery, Hans Katzberg from the University of Toronto, and Jeanne Teitelbaum from McGill University as new Associate Editors in neurology. I am very pleased that they agreed to join us and we will continue to have a very strong editorial team moving forward.

I am pleased to report that the impact factor of our journal has continued to increase. The 2013 journal impact factor, released in July 2014, is 1.599 . This represents a significant improvement over the 2012 impact factor of 1.332. The impact factors for the previous years from 2008 to 2011 ranged between 0.968 and 1.24. We are confident that our impact factor will continue to increase.

We are at a time of rapid changes in scientific publishing, with the development of many new, online-only journals in the past few years. As the only Canadian journal dedicated to neuroscience, we will continue to focus on new scientific and clinical information that helps to advance of our knowledge of the causes and management of neurological disorders. Our authors will benefit from our policy of no submission or publication charges and open access for all articles one year after publication. We are committed to maintaining a high publication standard and vigorous peer-review, and are very grateful to our reviewers who dedicated their time and effort to CJNS. As we continue to evaluate and implement further changes, I welcome your input to improve the journal.

Robert Chen

Editor-in-Chief, Toronto, Ontario, Canada 